\title{
Improvement of Verbal and Nonverbal Communication Skills of Nursing Students through Self-Objectification
}

\author{
Kim Mi-Won ${ }^{1}$ and Lee Hee-Joo ${ }^{2}$ \\ Department of Nursing, Sang-Myung University, Korea \\ ${ }^{1} k m w @ s m u . a c . k r,{ }^{2} l h j @ s m u . a c . k r$
}

\begin{abstract}
The purpose of this study was to investigate the effect of self-objectification process through video watching on interview process on the improvement of verbal and nonverbal communication skills of nursing students. The study method was an experimental study through pre-post test of the control group. The subjects were 52 nursing students in $C$ city. The results showed that the linguistic and nonverbal communication skills of the experimental group were significantly improved before and after the experiment. These results suggest that applying an objective assessment of their interview process is an effective way to improve communication skills in the field of nursing education.
\end{abstract}

Keywords: Communication, Ability, Skills, Standardized, Patient, Interview, Video, Analysis

\section{Introduction}

Recently, there has been a consensus in nursing and medical communities that the most important qualities required for medical personnel are effective communication and interview skills. Such consensus has led to the implementation of education on communication skills and medical conversation [1]. Education and training on communication are the processes that facilitate individuals to utilize their perception system to form meanings among people involved in a conversation, to understand the mutual interactions with each other, and to use them without awkwardness [2]. Although training on nurse-patient communication should emphasize practice-based trainings that aim to understand interviews with patients, there has been little effort to effectively reflect them in the curriculum. According to a study, for the medical students who completed clinical practice, their communication skills was improved overall, but their scores on active listening, expression of empathy, and understanding of the patient's point of view did not improve [3]. Such findings suggest that current curriculum may be inefficient in improving medical students' communication skills with their patients.

It is thought that the process of acquiring self-objectification through observing oneself can help nursing students improve their communication skills with patients. One way to achieve self-objectification is to record oneself performing the task and to watch the recorded video. This allows the comprehensive observation and evaluation of one's image and voice. Such self-objectification method assumes that the more information about oneself will improve one's behavior more [4]. Such a self-observation method aims to complement the traditional method of clinical practice that is centered on the instructor's verbal explanation and

Article history:

Received (October 16, 2017), Review Result (November 26, 2017), Accepted (January 13, 2018) 
demonstration, and it has been used in fields such as sports dance counseling to correct and improve learner's movement by recording and watching learner's performance [5]. Communication skill is not just about the linguistic contents but also a comprehensive practice that includes broad non-verbal aspects such as emotional expression, the manner of speech, and empathetic attitude. Therefore, by observing oneself objectively, one will be able to evaluate and improve the appropriateness of one's communication skills. The nursing department has made an effort so far to improve students' practical nursing skills including communication skills by adopting simulation training into the curriculum. Even though little research has been done on the educational methods that could improve both communication skills and nursing performance [6], self-observation method is expected be effective for communication education of nursing students.

Therefore, this study aimed to examine the training method that could improve practical communication skills and to propose such method to be implemented in the curriculum. Specifically, this study attempted to verify the effect of self-objectification process, which makes the nursing students record their communication scene and evaluate their performance by themselves, on improvement of verbal and nonverbal communication skills.

\section{Method}

\subsection{Research method}

This study applied the randomized control group pretest-posttest design to verify the effect of the self-objectification process on the verbal and nonverbal communication skills of nursing students by recording the interview scenes with the standardized patients and evaluating their skills based on the recorded video.

\subsection{Research procedure}

This study was conducted in the following procedures: development of a scenario, training of the standardized patients, development of a communication skill evaluation scale, preevaluation (recording and evaluation of the first interview), intervention on experimental group (video watching and self-evaluation), and post evaluation (recording and evaluation of the second interview).

\subsection{Evaluation tool for communication skill}

The communication skill evaluation tools for nursing assessment was based on the contents of the fundamental communication task suggested by the Kalamazoo consensus framework [7] and adopted the video interview evaluation tool developed by Kim [3] which is used for the video analysis of the medical student interview process. Some descriptions were revised to administer it to nursing students. The items in the evaluation tool consisted of 20 items evaluating verbal communication and 8 items evaluating nonverbal communication. The verbal communication items were evaluated by the researcher through analyzing the transcripts, and the non-verbal communication items were evaluated by the researchers through watching recorded video. Each item was evaluated on three scales-performed, insufficient, and not performed-which were converted into 2, 1, and 0 points, respectively. The evaluation basis for each item was set based on relevant measures. The reliability of the instrument in this study was .81 . 


\subsection{Data analysis}

Analyses were conducted using SPSS 21.0 at the .05 significance level. $\chi 2$ test and t-test were used to examine the general characteristics of the control group and experimental group and the homogeneity in communication skills. After the intervention, a t-test was conducted to compare communication skills of the control group and the experimental group. Lastly, pre- and post- communication skills in the experimental group were compared using a paired t-test.

\subsection{Research ethics}

This research was approved by S University Institutional Review Board (SMUIRB-AP2016-004). The research objectives and procedures were explained to all participants, and those who agreed to the consent form were included in the study. It was informed that the participation in this study will not affect the course grade and that recorded videos will be used for research purposes only and will be deleted shortly after the analyses in considering the ethical aspect of this study.

\section{Result}

\subsection{Test for homogeneity}

The test for homogeneity between the experimental group and the control group before the intervention showed that there was no significant difference between the experimental group and the control group in terms of gender, age, verbal and nonverbal communication skills.

Table 1. Homogeneity between the experimental and control groups $(n=52)$

\begin{tabular}{|c|c|c|c|c|c|}
\hline \multirow[b]{2}{*}{ Variables } & & Experimental group & Control group & \multirow[b]{2}{*}{ t or $X^{2}$} & \multirow[b]{2}{*}{$\mathrm{p}$} \\
\hline & & $\begin{array}{l}\text { Frequency }(\%) \\
\text { or Mean }( \pm S D)\end{array}$ & $\begin{array}{l}\text { Frequency }(\%) \\
\text { or Mean }( \pm \text { SD) }\end{array}$ & & \\
\hline \multirow{2}{*}{ Gender } & Female & $24(92.0 \%)$ & $21(80.7 \%)$ & \multirow{2}{*}{1.486} & \multirow{2}{*}{.223} \\
\hline & Male & $2(8.0 \%)$ & $5(19.3 \%)$ & & \\
\hline \multirow{3}{*}{ Age } & Under 20yrs & $15(58.0 \%)$ & $11(42.0 \%)$ & \multirow{3}{*}{1.256} & \multirow{3}{*}{.534} \\
\hline & $21-22 y r s$ & $7(27.0 \%)$ & $10(38.5 \%)$ & & \\
\hline & Above 23yrs & $4(15.0 \%)$ & $5(19.0 \%)$ & & \\
\hline \multirow{2}{*}{$\begin{array}{c}\text { Communication } \\
\text { skill }\end{array}$} & Verbal & $1.15( \pm 0.35)$ & $0.86( \pm 0.19)$ & -1.137 & .261 \\
\hline & Nonverbal & $1.26( \pm 0.40)$ & $1.15( \pm 0.35)$ & -1.057 & .296 \\
\hline
\end{tabular}

\subsection{Differences in communication skills between the experimental group and control group after the intervention}

Results regarding differences in communication skills between the experimental group and control group after the intervention are shown in [Table 2].

There was a significant difference in the nonverbal communication skills between the experimental group (mean $\pm S D, 1.67 \pm 0.26)$ and the control group $(1.23 \pm 0.46)$ after the intervention $(\mathrm{t}=4.28, \mathrm{p}<.001)$. Verbal communication skills also showed significant differences between the experimental group $(1.33 \pm 0.28)$ and control group $(0.96 \pm 0.27)$ after 
the intervention $(\mathrm{t}=4.84, \mathrm{p}<.001)$. This shows that self-objectification intervention improves both nonverbal and verbal communication skills.

Table 2. Communication skills after intervention $(n=52)$

\begin{tabular}{|c|c|c|c|c|c|}
\hline \multirow{2}{*}{ Variables } & & Experimental group & $\begin{array}{l}\text { Control } \\
\text { Group }\end{array}$ & \multirow{2}{*}{$\mathrm{t}$} & \multirow{2}{*}{$\begin{array}{c}\mathrm{P} \\
\text { (two-tailed) }\end{array}$} \\
\hline & & Mean \pm SD & Mean \pm SD & & \\
\hline \multirow{2}{*}{$\begin{array}{l}\text { Communication } \\
\text { skill }\end{array}$} & Nonverbal & $1.67 \pm 0.26$ & $1.23 \pm 0.46$ & 4.28 & $\mathrm{p}<.001$ \\
\hline & Verbal & $1.33 \pm 0.28$ & $0.96 \pm 0.27$ & 4.84 & $\mathrm{p}<.001$ \\
\hline
\end{tabular}

\subsection{A comparison of pre-post score difference in communication skills}

Results for comparisons of pre- and post- communication skill scores in the experimental group and the control group are shown in [Table 3].

Table 3. A comparison of pre - post score difference $(n=52)$

\begin{tabular}{|c|c|c|c|c|c|c|c|}
\hline \multirow{2}{*}{ Variables } & & & \multicolumn{2}{|c|}{ Experimental group $(n=26)$} & \multicolumn{3}{|c|}{ Control group $(n=26)$} \\
\hline & & & Mean \pm SD & $\mathrm{p}$ & Mean \pm SD & $\mathrm{T}$ & $\mathrm{P}$ \\
\hline \multirow{6}{*}{ skills } & \multirow{3}{*}{ Nonverbal } & Pre. & $1.26 \pm 0.40$ & \multirow{3}{*}{-5.676} & $1.15 \pm 0.35$ & \multirow{3}{*}{-.819} & \multirow{3}{*}{.420} \\
\hline & & Post. & $1.67 \pm 0.26$ & & $1.23 \pm 0.46$ & & \\
\hline & & Difference & $-0.40 \pm 0.36$ & & $-0.07 \pm 0.45$ & & \\
\hline & \multirow{3}{*}{ Verbal } & Pre. & $0.93 \pm 0.28$ & \multirow{3}{*}{$-8.700 \mathrm{p}<.001$} & $0.86 \pm 0.19$ & \multirow{3}{*}{-2.298} & \multirow{3}{*}{.030} \\
\hline & & Post. & $1.33 \pm 0.28$ & & $0.96 \pm 0.27$ & & \\
\hline & & Difference & $-0.40 \pm 0.24$ & & $-0.11 \pm 0.23$ & & \\
\hline
\end{tabular}

In the experimental group, there were significant differences in the pre- and post-scores in both nonverbal $(\mathrm{t}=-5.676, \mathrm{p}<.001)$ and verbal $(\mathrm{t}=-8.700, \mathrm{p}<.001)$ communication skills. The control group, on the other hand, showed no significant difference in nonverbal communication skills $(\mathrm{t}=-.819, \mathrm{p}=.420)$, but showed significant difference in verbal communication skills $(\mathrm{t}=-2.298, \mathrm{p}=.030)$.

\section{Discussion}

Results of this study show that the nonverbal skills were significantly higher in the experimental group $(1.67 \pm 0.26)$ than in the control group (1.23 \pm 0.46$)$ after the intervention $(p$ $<.001)$. Also, the verbal skills were higher in the experimental group than in the control group $(\mathrm{p}<.001)$. These results indicate that self-objectification intervention which involves watching and evaluating one's own recorded performance has a significant effect on improving communication skills.

This suggests that self-objectification which involves recording one's interview process and evaluating it helps improve nonverbal and verbal communication skills. Verbal communication involves having an intention to communicate with others, conveying thoughts, being able to speak about sensitive matters, talking about how one feels, discussing and debating. Nonverbal communication involves reading emotions from facial expressions or gestures of the other person and communicating using eye-contacts and gestures. By watching recorded video of oneself, the participants in the experimental group can have an opportunity to properly correct one's behavior since they can see their own facial expressions, emotions, 
and responses to patient's answer through the process of self-objectification. Such findings are consistent with the findings from O'Conner, Abert, and Thomas [8] which reported that the process of recording and reviewing VTRs in various scenes that mirror actual situations improve nursing intervention skills.

In terms of the pre- and post-intervention differences in communication skills between the experimental group and the control group, the control group did not show significant change in the nonverbal skill before and after the intervention, but they showed significantly improved verbal skills after the intervention $(\mathrm{p}=.030)$. In the experimental group, both nonverbal $(\mathrm{p}<.001)$ and verbal $(\mathrm{p}<.001)$ communication skills significantly increased.

The improvement of the verbal skills in the control group may be because of the class that they took. In the class, between the pre- and post-intervention, the students performed three practices of interviews by taking the role of the patient and the nurse in turn besides the lecture, and such practices seem to have influenced the control group's communication skills. Choi et al., without using self-objectification method, compared the improvement of communication skills between the experimental group who used standardized patients and the control group, and reported that the experimental group showed significantly higher communication skills.

The health assessment practice training using the standardized patients are thought to improve students' communication skills because it provides more similar situation to the actual scene than the current training model and gives students an opportunity to use verbal and nonverbal communication. The self-observation method using video tapes has been widely used from the past since it has various advantages. In recent years, video tape recording methods have been used in combination with self-assessment procedures to improve the efficiency of self-evaluation [5]. A study using video recording method showed that this method leads to improvement in expressiveness in a short period of time. When students performed self-observation by watching their performance recorded in a video with an emphasis on expressiveness, they quickly recognized their problems in expressiveness. Through self-observation, students showed strong dissatisfaction with the lack of expressiveness in their performance which led to a strong motivation to improve their problems. Also, watching the beautiful expressions of other students helped the students improve on their expressiveness. Through several self-observations and subsequent performances, students showed much improved performance in terms of their expressiveness [5].

This study suggests that the verbal communication skills can be improved through practice, but the nonverbal skills are less likely to be improved from mere practice. Similarly, the lecture-based theoretical teaching may have a positive effect on verbal communication skills, but continuous and repetitive trainings involving self-objectification and correction seem necessary for the nonverbal skills to be improved and to become habitual.

Thus, the use of standard patients in patient interview trainings among nursing students is a very effective training method that provides a similar environment with the actual interview scene and thereby leads to changes in habitual behaviors. Verbal communication skills can be improved through theoretical lessons, but nonverbal communication skills can be effectively improved by implementing self-objectification method which involves seeing their performance directly and changing their behavior by having objective evaluation criteria. In conclusion, it is considered that the method of self-objectification is a very effective way to improve communication skills. 


\section{References}

[1] B.N. Do, Y.S. Kim, and H.M. Kim, "The interpersonal relationship and communication,” Jungdam media, Seoul, (2009)

[2] J.S. Ju, "The effects of the communication training program for university student's communication and human relationships", M.S. thesis, Kyungpook University, Daegu, (2006)

[3] S.Y. Kim, "Communication skills and empathic response among 4th year medical students: Videotape analysis of real patient consultation," M.S. thesis, Department of Family Medicine and the Graduate School of Sungkyunkwan University, (2009)

[4] D.E. Sanb(v)orn III, H.F. Pyke, and C.J. Sanborn, "Videotape playback and psychotherapy: A review," Psychotherapy: Theory, Research and Practice, vol.12,no. 2, pp.179-186, (1975)

[5] Y. Kim, "A study on the effects of video self-observation learning on dance class," M.S. thesis, Ewha Womans University, Seoul, Korea, (2010)

[6] S.J. Choi, M.S. Kwon, S.H.Kim, H.M. Kim, Y.S. Jung, and G.Y. Jo, "Effects of using standardized patients on nursing competence, communication skills, and learning satisfaction in health assessment," Korean of Academic Society of Nursing Education, vol.19, no.1, pp.97-105, February, (2013)

[7] G. Makoul, "Essential elements of communication in medical encounters: The kalamazoo consensus statement," Academic Medicine, vol.76, no.4, pp.390-393, (2001)

[8] F.W. O'conner, M. Albert, and M.D. Thoma, "Incorporation standardized patients into a psychosocial nursing practitioner programs," Archives of Psychiatric Nursing, vol.13, no.5, pp.240-247, (1999) 